\title{
HP1717 Contributes to Streptococcus suis Virulence by Inducing an Excessive Inflammatory Response and Influencing the Biosynthesis of the Capsule
}

\author{
Liang Liu ${ }^{1}$, Qiang Zhang ${ }^{1}$, Zhongmin $X u^{1}$, Jingjing Huang ${ }^{1}$, Weifeng Zhu ${ }^{1}$, Anding Zhang ${ }^{1,2}$, \\ Xiaomei Sun ${ }^{2}$ and Meilin Jin ${ }^{1,2,3, *}$ \\ 1 Unit of Animal Infectious Diseases, National Key Laboratory of Agricultural Microbiology, College of \\ Veterinary Medicine, Huazhong Agricultural University, Wuhan 430070, China; robin2371@163.com (L.L.); \\ 05yisan@163.com (Q.Z.); xzmjack@126.com (Z.X.); hjingjing111@gmail.com (J.H.); \\ zhuweifeng8@126.com (W.Z.); andye8019@mail.hzau.edu.cn (A.Z.) \\ 2 Key Laboratory of Preventive Veterinary Medicine in Hubei Province, The Cooperative Innovation Center \\ for Sustainable Pig Production, Wuhan 430070, China; sunxm320@126.com \\ 3 Key Laboratory of Development of Veterinary Diagnostic Products, Ministry of Agriculture, \\ Wuhan 430070, China \\ * Correspondence: jinmeilin@mail.hzau.edu.cn; Fax: +86-27-87286905
}

Received: 27 August 2019; Accepted: 1 November 2019; Published: 3 November 2019

\begin{abstract}
Streptococcus suis 2 (SS2) is an important zoonotic pathogen that substantially harms the swine industry and poses threats to human health. Excessive inflammation is considered to be a hallmark of SS2 infection because it is responsible for most clinical signs of SS2, especially streptococcal toxic shock-like syndrome. However, the current knowledge of SS2-induced excessive inflammation remains limited. In this study, we identified HP1717 as a novel extracellular pro-inflammatory protein in SS2 that can induce robust expression of inflammatory cytokines in RAW264.7 macrophages. Notably, the pro-inflammatory ability of HP1717 was dose-dependent and heat-sensitive, and it required the recognition of Toll-like receptor 2 (TLR2) and the phosphorylation of both extracellular signal-regulated kinases 1/2 (ERK1/2) and nuclear factor kappa-light-chain-enhancer of activated B cells (NF-kB). Further, by constructing a deletion mutant, we demonstrated that HP1717 significantly influenced the biosynthesis of the bacterial capsule, which plays a critical role in the virulence of SS2 by interfering with the ability of host immune cells to phagocytize and kill the pathogen. Indeed, the mutant strain displayed reduced resistance to whole-blood killing compared with the wild strain. Finally, murine experiments indicated that the deletion of $h p 1717$ in SS2 reduced the lethality, pro-inflammatory activity, and bacterial loads in mice. Collectively, our data reveal HP1717 as a novel virulence-related factor of SS2 that can induce an excessive inflammatory response and significantly affect the bacterial capsule, thus expanding our understanding of the pathogenesis of S. suis.
\end{abstract}

Keywords: Streptococcus suis; inflammatory; streptococcal toxic shock-like syndrome; virulence; capsule

\section{Introduction}

Streptococcus suis (S. suis) is an important swine pathogen that is responsible for tremendous financial losses in the pig industry, and it presents a severe threat to human health [1]. Among the 29 described serotypes on the basis of capsular polysaccharide (CPS) antigens, serotype 2 (SS2) is frequently isolated from diseased pigs in most countries [2]. Since the first report on the pathogen was published in 1954, S. suis infection has been reported in more than 30 countries and regions [3]. Moreover, its prevalence in human populations has been increasing over the past 20 years. Between 2002 and 2013 , there were 1642 cases of human infections in 34 countries, 90\% of which occurred in Asia [1]. In China, 
S. suis caused two large-scale human infections in Jiangsu and Sichuan, infecting more than 240 people, 14 and 38 of whom died in 1998 and 2005, respectively [4]. Among the patients who died from the disease in 2005, 97.4\% had streptococcal toxic-shock-like syndrome (STSLS) [5], and the mortality of patients with toxic shock was 62\% [6]. Later, patients in Vietnam and Thailand presented similar symptoms [7], and these cases received considerable attention worldwide. Sequencing analysis showed that the two epidemics in China were caused by sequence type 7 (ST7) rather than the widespread pathogenic bacterial strain sequence type 1 (ST1) in Europe. Further investigation indicated that ST7 could stimulate the massive production of pro-inflammatory cytokines [8], which significantly contribute to the development of STSLS [9]. The results of these analyses indicated that Asia was facing a novel, highly virulent mutant strain of SS2 [10].

Previous studies have reported more than 100 virulence-related factors of SS2, such as subtilisin-like protease, muramidase-released protein, suilysin, and its CPS [11]. CPS is considered to play a particularly critical role in the virulence of SS2 because it can protect bacteria from host immune cells by preventing phagocytosis and bacterial death [12]. Despite these studies on SS2, the current understanding of its pathogenic mechanism remains limited, and the bacterial factors that lead to STSLS are particularly elusive [13]. STSLS was originally caused by group A Streptococcus infection and primarily associated with superantigens [14]. However, genome analysis showed that SS2 had neither superantigens nor homologous genes, suggesting that several unique molecular mechanisms could be responsible for STSLS due to SS2 [14]. A previous study indicated that excessive inflammation played a key role in the pathogenesis of SS2-induced septicemia, meningitis, STSLS, and sudden death [15]. The identification of several pro-inflammatory proteins (e.g., HP0459 and HP1330) has enhanced our understanding of STSLS $[13,16]$, although this knowledge is not complete. Thus, further details on the mechanism of the excessive inflammation caused by SS2 will help us better understand SS2-induced STSLS.

In the current study, we identified the potent pro-inflammatory protein HP1717 in SS2 and studied its pattern recognition receptor and signal transduction pathway. We also demonstrated that the deletion of HP1717 in SS2 could significantly increase the whole-blood killing of the pathogen by affecting the biosynthesis of CPS. Our study not only reveals a novel virulence-related factor of SS2 but also considers, for the first time, both excessive inflammation and the bacterial capsule at the same time. Therefore, our results provide new insights into the pathogenesis of SS2 and further our understanding of this pathogen.

\section{Materials and Methods}

\subsection{Bacterial Strains, Plasmids, and Growth Conditions}

The details of the bacterial strains and plasmids used in this study are shown in Table 1. SS2 strain $05 \mathrm{ZY}$ was selected as the wild-type (WT) strain, which is highly pathogenic to mice and pigs and can cause STSLS. The $05 Z Y$ strain and the deletion mutant $\Delta 1717$ were cultured in tryptic soy broth (TSB) or on tryptic soy agar (TSA) plates (Difco, MI, USA) with $10 \%$ newborn bovine serum (Sijiqing Biological Engineering Materials Co., Ltd., Hangzhou, China) at $37^{\circ} \mathrm{C}$.

Table 1. Summary of the bacterial strains and plasmids used in this study.

\begin{tabular}{|c|c|c|c|}
\hline Group & Name & Characteristics and Functions & Sources or References \\
\hline \multicolumn{4}{|c|}{ Strains } \\
\hline & 05ZY & Streptococcus suis serotype 2 wild type & Laboratory collection \\
\hline & $\Delta 1717$ & $\Delta 1717$-deletion mutant strain & This study \\
\hline & Escherichia coli $\mathrm{DH} 5 \alpha$ & Cloning host for recombinant vector & TIANGEN \\
\hline & E. coli BL21 & Expression host for recombinant protein & TIANGEN \\
\hline \multicolumn{4}{|c|}{ Plasmids } \\
\hline & pSET4s & E. coli-S. suis shuttle vector; Spcr & Laboratory collection [17] \\
\hline & pET28a & Expression vector; Kan & TIANGEN [13] \\
\hline
\end{tabular}




\subsection{Cell Culture}

RAW 264.7 macrophages were cultured in Dulbecco's modified Eagle's medium supplemented with $10 \%$ fetal bovine serum (Gibco, Waltham, MA, USA) at $37^{\circ} \mathrm{C}$ in a $5 \% \mathrm{CO}_{2}$ atmosphere. The cells were plated at a density of $10^{6}$ cells per well in 12-well plates. Mouse primary macrophage were isolated according to previous research [13]. Toll-like receptor 2 (TLR2)-deficient, TLR4-deficient, and WT mice were injected intraperitoneally (i.p.) with $4 \%$ thioglycolate (TLR2-deficient and TLR4-deficient mice were obtained from the Collaborative Innovation Center of Model Animal, Wuhan University). Peritoneal exudate cells were harvested 4 days later and identified by microscopic analysis and non-specific esterase staining. When $>90 \%$ of the exudate cells were identified as macrophages, the cells were plated at a density of $10^{6}$ in 12 -well plates.

\subsection{Purification of the HP1717 Protein}

The $h p 1717$ gene from the 05ZY genome was amplified using PCR. The primers are shown in Table 2. The cloned gene was inserted into the prokaryotic expression plasmid pET28a and transformed into the Escherichia coli BL21 strain. Isopropyl-b-d-thiogalactopyranoside $(0.2 \mathrm{mM})$ was added to the cells to induce protein expression, and the culture was incubated for $4 \mathrm{~h}$ at $37^{\circ} \mathrm{C}$. Then, the recombinant protein was purified by Ni-NTA agarose chromatography. The endotoxin in the purified protein was removed using an Endotoxin Removal Kit (Genmed Scientifics Inc., WILMINGTON, DE, USA) and measured by a Quantitative Chromogenic Tachypleus Amebocyte Lysate for Endotoxin Detection Kit (Chinese Horseshoe Crab Reagent Manufactory Co., Ltd., Xiamen, China). Next, the protein was filtered with a $0.22 \mu \mathrm{m}$ membrane and stored at $-80^{\circ} \mathrm{C}$ for subsequent experiments.

Table 2. Oligonucleotide primers used in this study.

\begin{tabular}{|c|c|c|}
\hline Primers & Primers Sequence $\left(5^{\prime}-3^{\prime}\right)$ & Functions or PCR Product \\
\hline hp1717-1 & CCCGAATTCATGTCGATTGTTGTAGTGGCA(EcoRI) & \multirow{2}{*}{$\begin{array}{l}\text { For amplification of the } h p 1717 \\
\text { ORF gene }\end{array}$} \\
\hline hp1717-2 & CCCAAGCTTTTACTCATTATTAAGATGTGCATTTAC(HindIII) & \\
\hline hp1717L1 & CGCGGATCCCTACTGGGTTGTCGGTGGT(BamHI) & \multirow{2}{*}{ Upstream border of $h p 1717$} \\
\hline hp1717L2 & AACACATTGTCTCTGTTATCATTCTTAAAACAAAATTATGTGGTT & \\
\hline hp1717R1 & GATAACAGAGACAATGTGTTTAGCGGCATTATCTTGTTTT & \multirow{2}{*}{ Downstream border of $h p 1717$} \\
\hline hp1717R2 & CCCAAGCTTTAAGGGACAGGGAGTGGG(HindIII) & \\
\hline MCP-1-1 & AGAAGGAATGGGTCCAGACATA & \multirow{2}{*}{ For qRT-PCR assay } \\
\hline MCP-1-2 & GTGCTTGAGGTGGTTGTGGA & \\
\hline TNF- $\alpha-1$ & GAGTGACAAGCCTGTAGCCC & \multirow{2}{*}{ For qRT-PCR assay } \\
\hline TNF- $\alpha-2$ & GACAAGGTACAACCCATCGG & \\
\hline IL-1 $\beta-1$ & TCATTGTGGCTGTGGAGAAGC & \multirow{2}{*}{ For qRT-PCR assay } \\
\hline IL-1 $\beta-2$ & TCATCTCGGAGCCTGTAGTGC & \\
\hline GAPDH-1 & TGGCCTTCCGTGTTCCTAC & \multirow{2}{*}{ For qRT-PCR assay } \\
\hline GAPDH-2 & TGAAGTCGCAGGAGACAACC & \\
\hline P1 & TGGAAATGTTCAAGTCAACC & \multirow{2}{*}{ For PCR to detect the gdh } \\
\hline P2 & CGTTTTTCTTTGATGTCCAC & \\
\hline P3 & CTACGAACTGCTAACA & \multirow{2}{*}{ For PCR to detect the pSET4s } \\
\hline P4 & GAATACATACGAACAAAT & \\
\hline P5 & CCAAAGATGCCAAGGT & \multirow[t]{2}{*}{ For PCR to detect the $h p 1717$} \\
\hline P6 & ATCGCCAAAGCACTTC & \\
\hline P7 & ATTCGTGGATTACCTG & \multirow{2}{*}{ External primers of $h p 1717$ ORF } \\
\hline P8 & TACCATCAAGCTCGTC & \\
\hline $16 \mathrm{~s}-1$ & CAGAAAGGGACGGCTAA & \multirow[t]{2}{*}{ For amplification of the 16 s gene } \\
\hline $16 \mathrm{~s}-2$ & CGGCTGGCTCCTAAAA & \\
\hline
\end{tabular}


Table 2. Cont.

\begin{tabular}{lcc}
\hline Primers & Primers Sequence $\left(\mathbf{5}^{\prime} \mathbf{-} \mathbf{3}^{\prime} \mathbf{)}\right.$ & Functions or PCR Product \\
\hline $16 \mathrm{~s}-\mathrm{rt}-1$ & AGATGGACCTGCGTTGTATT & For qRT-PCR assay \\
\hline $16 \mathrm{~s}-\mathrm{rt}-2$ & TCCGAAAACCTTCTTCACTC & For qRT-PCR assay \\
\hline $1717 \mathrm{rt}-1$ & TGGCATCTTTGGTTGA & \\
\hline $1717 \mathrm{rt}-2$ & CGAAAGGCTTGGACTA & \\
\hline $\begin{array}{l}\text { Underlined nucleotides denote enzyme restriction sites; Double-underlined nucleotides denote overlapping } \\
\text { sequences. }\end{array}$
\end{tabular}

\subsection{Flow Cytometry Analysis}

Flow cytometry analysis was used to detect HP1717 on the surface of $S$. suis bacterial cells, as previously described [18]. Briefly, the overnight cultures were grown in TSB to an OD600 of 0.6. Bacteria were washed twice in PBS, and the cell density was adjusted to approximately $10^{8} \mathrm{CFU} / \mathrm{mL}$. Bacterial suspensions were incubated with mouse anti-rHP177 or preimmune serum as control. After $1 \mathrm{~h}$, cells were washed three more times with PBS and then incubated with goat anti-mouse IgG-fluorescein isothiocyanate (FITC) (KPL) for $1 \mathrm{~h}$. This was followed by paraformaldehyde fixation for $30 \mathrm{~min}$. Then, the samples were detected using a flow cytometer (Becton Dickinson, CA, USA).

\subsection{RNA Extraction and $q R T-P C R$}

RAW 264.7 cells were treated with $1 \mu \mathrm{g} \cdot \mathrm{mL}^{-1} \mathrm{HP} 1717$ or $100 \mathrm{ng} \cdot \mathrm{mL}^{-1}$ lipopolysaccharide (LPS) for $6 \mathrm{~h}$, and then the total RNA of the cells was extracted using the TRIzol ${ }^{\circledR}$ reagent (Invitrogen, Paisley, UK). Complementary DNA was synthesized from $4 \mu \mathrm{g}$ of RNA by using AMV reverse transcriptase (Takara, Dalian, China). qRT-PCR was performed using ViiA ${ }^{\text {TM }} 7$ Software (Applied Biosystems, Waltham, MA, USA) with the SYBR Green PCR Kit (Roche, Basel, Switzerland). All the primers used in qRT-PCR are listed in Table 2. The relative levels of target gene expression were normalized with the GAPDH housekeeping gene using the $2^{-\Delta \Delta C t}$ method.

\subsection{Examination of Cytokines by ELISA}

The concentrations of IL-1 $\beta, \mathrm{MCP}-1$, and TNF- $\alpha$ in the cell culture supernatants or sera were determined using commercially available ELISA kits (BioLegend, San Diego, CA, USA) following the manufacturer's instructions the detection limits of IL- $1 \beta$, MCP-1, and TNF- $\alpha$ were 22,20 , and $8 \mathrm{pg} \cdot \mathrm{mL}^{-1}$, respectively.

\subsection{Determination of HP1717 Recognition Receptor}

To investigate which receptor was specifically responsible for HP1717-mediated cytokine upregulation, we first detected the mRNA levels of TLR2 and TLR4 after HP1717 stimulation by qRT-PCR. Next, antibody blocking assays were performed to verify the results of qRT-PCR. Briefly, after pretreatment with $8 \mu \mathrm{g}$ of an anti-TLR2 (BioLegend, San Diego, CA, USA) or anti-TLR4 (BioLegend) antibody for $30 \mathrm{~min}$, RAW264.7 cells were incubated with $1 \mu \mathrm{g} \cdot \mathrm{mL}^{-1} \mathrm{HP} 1717$ for $6 \mathrm{~h}$. The concentrations of IL-1 $\beta$, MCP-1, and TNF- $\alpha$ in the culture supernatants were determined by ELISA. TLR2-/- and TLR4-/- macrophages isolated from TLR2-/- and TLR4-/- mice were also used to prove this result.

\subsection{Analysis of the HP1717-Induced Cell Signal Transduction Pathway}

For cell signaling analysis, 30 min prior to the addition of HP1717, RAW 264.7 cells were incubated with the following specific inhibitors: SB203580 (for p38 MAPK, $10 \mu \mathrm{M}$; Cayman Chemical, Michigan, USA), SP600125 (for JNK, $10 \mu \mathrm{M}$; Cayman Chemical), pyrrolidine dithiocarbamate (PDTC; for NF-KB, $20 \mu \mathrm{M}$; Sigma), LY294002 (for PI3K, $20 \mu \mathrm{M}$; Cayman Chemical), and U0126 (for ERK1/2, $10 \mu \mathrm{M}$; Cayman Chemical). After HP1717 stimulation for $6 \mathrm{~h}$, the culture supernatants were collected for ELISA to measure IL-1 $\beta$, MCP-1, and TNF- $\alpha$. According to the conditions of cytokine expression in each group, we performed a preliminary screen for the signal transduction molecule induced by HP1717. To verify 
the above analysis results, we performed Western blotting to analyze the phosphorylation of signal transduction molecules activated by HP1717. Briefly, after being stimulated with $1 \mu \mathrm{g} \cdot \mathrm{mL}^{-1} \mathrm{HP} 1717$ for 6 h, RAW 264.7 cells were washed once with cold PBS and incubated on ice for 15 min using radioimmunoprecipitation assay lysis buffer with phosphatase inhibitors (Roche, Basel, Switzerland). The supernatants were collected, and their protein concentrations were quantified by the Bradford protein assay. Then, $20 \mu \mathrm{g}$ of proteins were resolved on a $12 \%$ sodium dodecyl sulfate-polyacrylamide gel electrophoresis (SDS-PAGE) gel, followed by electrotransfer to a $0.22 \mu \mathrm{m}$ nitrocellulose membrane. After blocking of the NC membrane by $1 \%$ BSA for $1 \mathrm{~h}$ at $25^{\circ} \mathrm{C}$, these proteins were probed with specific antibodies against the phosphorylated forms of ERK1/2 and NF- $\mathrm{KB}$ p65 (Cell Signaling Technology, Beverly, MA, USA), and GAPDH was assessed as an internal control using anti-GAPDH antibody (PMK Biotechnology Co., Ltd, Wuhan, China). The bands were detected using a HRP-conjugated secondary antibody and an enhanced chemiluminescence (ECL) system (Amersham Life Science, Arlington Heights, IL, USA).

\subsection{Mutant Construction}

The deletion of HP1717 was performed as previously described [17]. The upstream and downstream homologous fragments of the $h p 1717$ gene were separately amplified using PCR. The two fragments were fused together using overlapping PCR and then digested using BamH I and HindIII. The obtained fragment was inserted into the shuttle plasmid pSET4s and transformed into E. coli DH5 $\alpha$. After cloning, the recombinant plasmid was electroporated into 05ZY. The potential mutant strain was screened for spectinomycin resistance and thermosensitive suicide of the pSET4s vector. The cells were then examined using P1/P2 (to detect $g d h$ ), P3/P4 (to detect the pSET4s vector), P5/P6 (to detect $h p 1717$ ), and P7/P8 (external primers to distinguish the size of the wild type and mutant).

\subsection{Gram Staining and Transmission Electron Microscope (TEM) Observation}

The Gram stain assay was carried out as previously described [19]. The cells were allowed to grow to an OD600 of 0.6 in THB at $37^{\circ} \mathrm{C}$, and Gram-stained cells were examined under a light microscope using oil immersion. TEM assays were performed in accordance with previously described methods [20]. Next, 05ZY and $\Delta 1717$ cells were harvested at OD600 of 0.6 and fixed with $2.5 \%$ glutaraldehyde overnight. The samples were then treated with $2 \%$ osmium tetroxide for $2 \mathrm{~h}$ and dehydrated by serial dilution using ethanol. The dehydrated cells were embedded in epoxy resin, and their morphological characteristics were observed using an H-7650 TEM (Hitachi, Tokyo, Japan).

\subsection{Whole-Blood Bactericidal Assay}

The whole-blood bactericidal experiment was performed as previously described [21]. First, 05ZY and mutant $\Delta 1717$ cells were cultured to mid-log phase (OD600 $=0.6)$. Next, $1 \times 10^{4} \mathrm{CFU}$ of $05 \mathrm{ZY}$ or an equal quantity of $\Delta 1717$ was added into $1 \mathrm{~mL}$ of whole blood for $2 \mathrm{~h}$ at $37^{\circ} \mathrm{C}$. At $0,0.5,1$, and $2 \mathrm{~h}$ post-incubation, bacterial counts were determined. The initial bacterial volume was set to $100 \%$, and the percentage of remaining bacteria was recorded at each time point. The assays were performed in triplicate and repeated three times.

\subsection{In Vivo Experiments and Immunohistochemistry}

This study was carried out in accordance with the recommendations of the Guide for the Care and Use of Laboratory Animals Monitoring Committee of Hubei Province, China, and the protocol was approved by the Committee on the Ethics of Animal Experiments at the College of Veterinary Medicine, Huazhong Agricultural University. For the in vivo experiments, 30 four-week-old male C57BL/6 mice were randomly divided into two groups, with 15 mice in each group. One group was intraperitoneally infected with $6 \times 10^{8} \mathrm{CFU}$ of $05 \mathrm{ZY}$, and the second group received an equal quantity of $\Delta 1717$ by the same method. After $6 \mathrm{~h}$, five mice in each group were sacrificed. The brains, lungs, livers, spleens, and kidneys were collected and fixed with $4 \%$ paraformaldehyde and sent to Hycell Biotechnology Company (Wuhan, China) for immunohistochemistry. Rehabilitation sera of pigs after 
infection with S. suis was used as a primary antibody (1:300), and HRP Goat Anti-Swine IgG (H+L) was used as the secondary antibody (1:200) (Abclonal, Wuhan, China). The disease onset and survival status in the remaining 20 mice were recorded for 1 week. In addition, 40 additional four-week-old female C57BL/6 mice were randomly assigned to two groups (20 mice per group) and challenged with a non-lethal dose $\left(2 \times 10^{8} \mathrm{CFU}\right.$ per mouse) of $05 \mathrm{ZY}$, and the other group was given an equal quantity of the $\Delta 1717$ strain. At $3,6,9$, and $12 \mathrm{~h}$ post-infection, five mice in each group were sacrificed to collect blood for ELISA detection of IL-1 $\beta$, MCP-1, and TNF- $\alpha$ production.

\subsection{Zymogram Analysis}

Zymogram analysis was performed according to the previous research with some modifications [22]. $600 \mathrm{~mL}$ of $S$. suis grown to the mid-log phase was collected and washed twice with PBS and then dissolved in 10\% SDS. After heating in boiling water for $30 \mathrm{~min}$, the sample was placed overnight at room temperature to ensure adequate dissolution. After centrifuging at $16,500 \times g$ for $20 \mathrm{~min}$, the supernatant was removed, and the precipitate was repeatedly washed with $\mathrm{ddH}_{2} \mathrm{O}$ to remove SDS and finally resuspended in $10 \mathrm{~mL}$ of $\mathrm{ddH}_{2} \mathrm{O}$. Cells was added to a $12 \%$ SDS-PAGE resolving gel solution instead of water. BSA (negative control), Lysozyme (positive control) and HP1717 were loaded into each lane (samples were repeatedly loaded once for different staining), the running conditions of the gel were the same as those of the general PAGE gel $(80 \mathrm{~V}$ for concentrated gel and $120 \mathrm{~V}$ for separation gel). The gel was washed with distilled water twice and incubated in $\approx 300 \mathrm{~mL}$ of refolding buffer ( $25 \mathrm{mM}$ Tris- $\mathrm{HCl}$ and $1 \%(v / v)$ Triton $\mathrm{X}-100, \mathrm{pH} 7.4)$ with gentle shaking at $37^{\circ} \mathrm{C}$ for 12 to $14 \mathrm{~h}$. The gel was divided into two parts and stained with Coomassie Brilliant Blue and Methylene Blue, respectively.

\subsection{Statistical Analysis}

Statistics for the survival assay were done with the log-rank test (Mantel-Cox). Other statistical analyses were performed by one-way or two-way ANOVA, followed by a multiple comparison. All experiments were performed at least three times, and data are expressed as the mean $\pm \mathrm{SD}$. A $p$-value $<0.05$ is considered significant. In the figures, ${ }^{*} p<0.05,{ }^{* *} p<0.01$, and ${ }^{* * *} p<0.001$. NS means no significance

\section{Results}

\subsection{Characterization of S. suis 2 HP1717}

Previous studies have indicated that the gene SSU05_1717 in the genome of S. suis 2 Chinese strain 05ZYH33 encodes a periplasmic solute-binding protein (GenBank accession number: ABP90683) that consists of 365 amino acid residues [4]. Analysis of the 47 genomes of different isolates of S. suis that were completely sequenced in NCBI (https://www.ncbi.nlm.nih.gov/genome/genomes/199?) has shown that all of them contain $h p 1717$, suggesting that this gene is widespread in S. suis. Further amino acid sequence homology analysis showed that HP1717 has certain similarities with many Gram-positive and negative bacteria. For example, the similarity between HP1717 and the homologous protein of S.pneumoniae (GenBank accession number: A0A0H2ZLQ1.1, Figure S1A) is 54\%, and the similarity with the homologous protein of S. pyogenes (GenBank accession number: SQF37078.1; Figure S1B), Staphylococcus aureus (GenBank accession number: SUL86689.1; Figure S1C), Bacillus vallismortis (GenBank accession number: WP_121642973.1; Figure S1D), and Escherichia coli (GenBank accession number: NP_415615.1; Figure S1E) is 57\%, 59\%, 37\%, and 27\%, respectively.

\subsection{HP1717 is Expressed on the Surface of S. suis 2}

Previous studies have predicted HP1717 to be a secreted protein, but we did not find a signal peptide in our prior work [23]. To determine whether the protein was expressed on the cell surface of S. suis 2, we performed flow cytometry. As shown in Figure S2, the mean fluorescence intensity (MFI) of S. suis 2 treated with mouse anti-HP1717 sera (B) was significantly higher than that of bacteria 
treated with preimmune serum (A). This indicates that HP1717 is not only expressed in 05ZY but also located on the bacterial cell surface.

\subsection{HP1717 Induces Potent Expression of Pro-Inflammatory Cytokines in RAW264.7 Cells}

HP1717 contains 365 amino acids and has an estimated molecular mass of approximately $40 \mathrm{kDa}$. SDS-PAGE (Figure 1A) and Western blotting (Figure 1B) analyses of the recombinant protein with an anti-His tag monoclonal antibody indicate that HP1717 was successfully expressed and purified. After removing endotoxins, the protein concentration was $2.5 \mathrm{mg} \cdot \mathrm{mL}^{-1}$, and the endotoxin level was $0.02 \mathrm{EU} / \mathrm{mL}$. Next, the results of both the quantitative real-time polymerase chain reaction (qRT-PCR) and the enzyme-linked immunosorbent assay (ELISA) analysis showed that HP1717 induced the massive expression of IL-1 $\beta$, MCP-1, and TNF- $\alpha$ (Figure 2A,B), indicating that HP1717 led to a potent pro-inflammatory response in RAW264.7 cells.

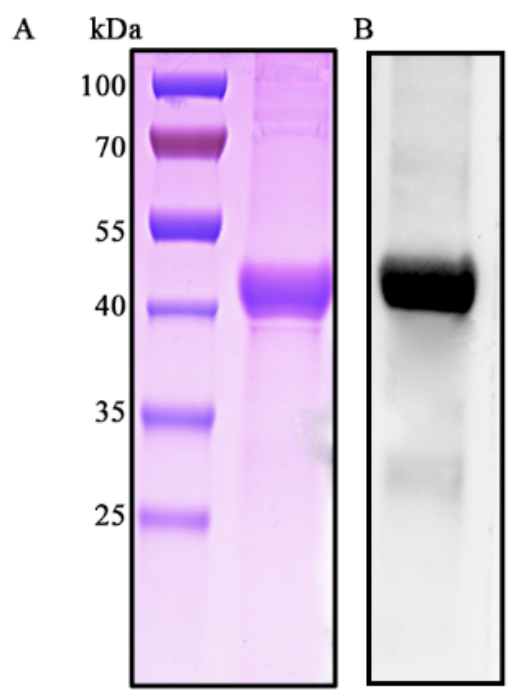

Figure 1. Purification of the recombinant HP1717 protein. (A) SDS-PAGE analysis. (B) Western blot analysis: the blot was probed with an anti-His tag monoclonal antibody (Cali-Bio).

\subsection{The Pro-Inflammatory Activity of HP1717 is Dose-Dependent and Heat-Sensitive}

To investigate whether the dose and activity of HP1717 affect its pro-inflammatory ability, the expressions of IL-1 $\beta$, MCP-1, and TNF- $\alpha$ induced by different concentrations of HP1717 were measured by qRT-PCR (Figure 3A). The results show that higher concentrations of HP1717 induced higher levels of cytokine expression, indicating that the pro-inflammatory activity of HP1717 is dose-dependent. After pretreating the protein at $100^{\circ} \mathrm{C}$ for $10 \mathrm{~min}$ [13], RAW264.7 cells were incubated with the heat-treated HP1717. We found that heat-treated HP1717 failed to stimulate the expression of IL-1 $\beta$, MCP-1, and TNF- $\alpha$, contrary to unheated HP1717 (Figure 3B). These findings indicate that the pro-inflammatory activity of HP1717 is heat-sensitive.

\subsection{The Pro-Inflammatory Role of HP1717 Depends on the Recognition of TLR2}

The qRT-PCR results show that TLR2 transcription was significantly upregulated in RAW264.7 cells stimulated by HP1717, but TLR4 transcription did not significantly change (Figure 4A). Antibody blocking experiments indicate that the pro-inflammatory effect of HP1717 almost disappeared when RAW264.7 cells were pretreated with the TLR2 antibody (Figure 4B). In addition, macrophages isolated from TLR2 ${ }^{-/-}$or TLR4 ${ }^{-/}$mice were used to evaluate the pro-inflammatory activity of HP1717. The results indicated that HP1717 could stimulate significant pro-inflammatory responses in WT and $\mathrm{TLR}^{-/-}$macrophages, but not in TLR2 ${ }^{-/-}$macrophages (Figure $4 \mathrm{C}$ ). Our results demonstrate that the pro-inflammatory ability of HP1717 depends on TLR2. 
A

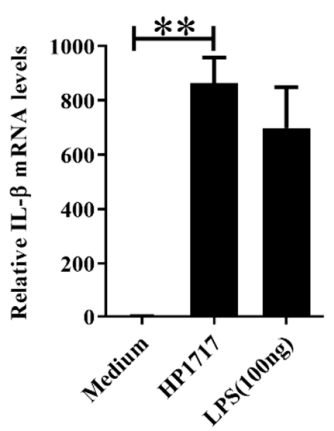

B

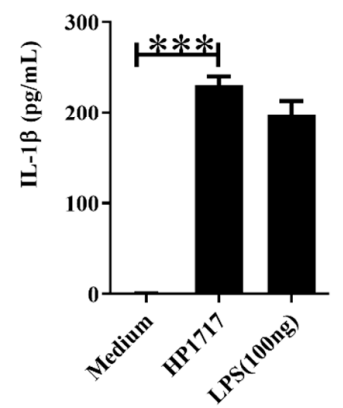

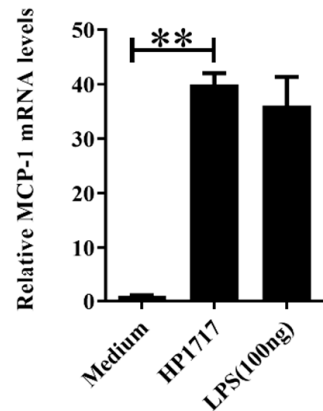

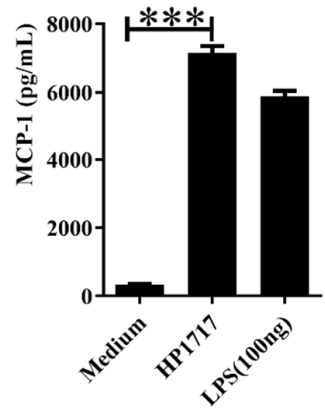

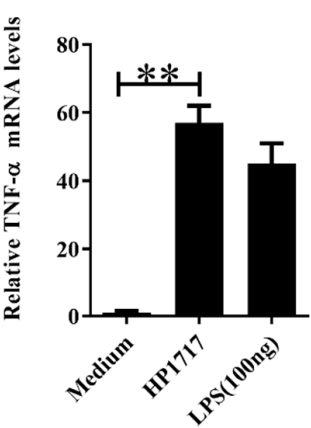

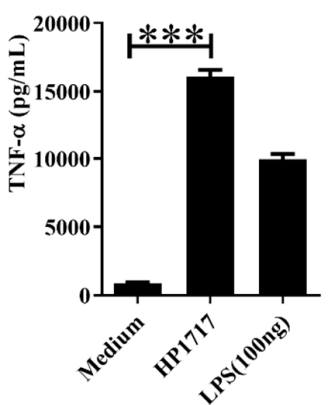

Figure 2. Induction of cytokine mRNA transcription and protein expression in RAW 264.7 macrophages after stimulation with recombinant HP1717. RAW 264.7 macrophages were treated with $100 \mathrm{ng} \cdot \mathrm{mL}^{-1}$ lipopolysaccharide (LPS) (positive control), $1 \mu \mathrm{g} \cdot \mathrm{mL}^{-1} \mathrm{HP} 1717$ protein, or culture medium (negative control). (A) The cytokine mRNA levels were determined by qRT-PCR, and (B) the protein levels of IL-1 $\beta$, MCP-1, and TNF- $\alpha$ in the culture supernatants were determined by enzyme-linked immunosorbent assay (ELISA). ${ }^{* *} p<0.01,{ }^{* * *} p<0.001$.

A

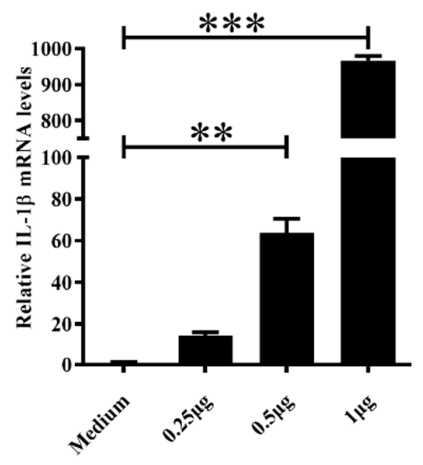

B

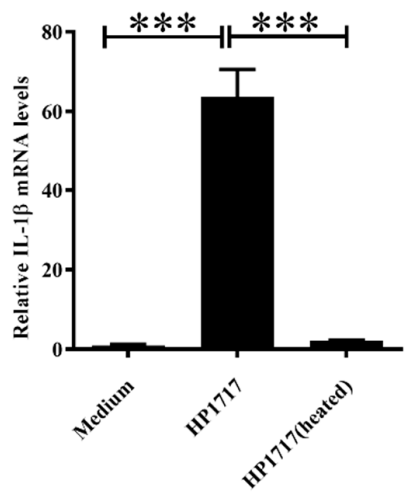

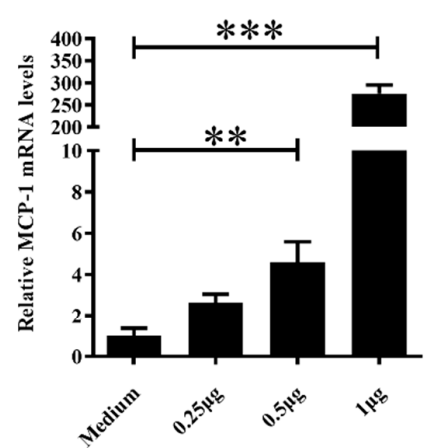
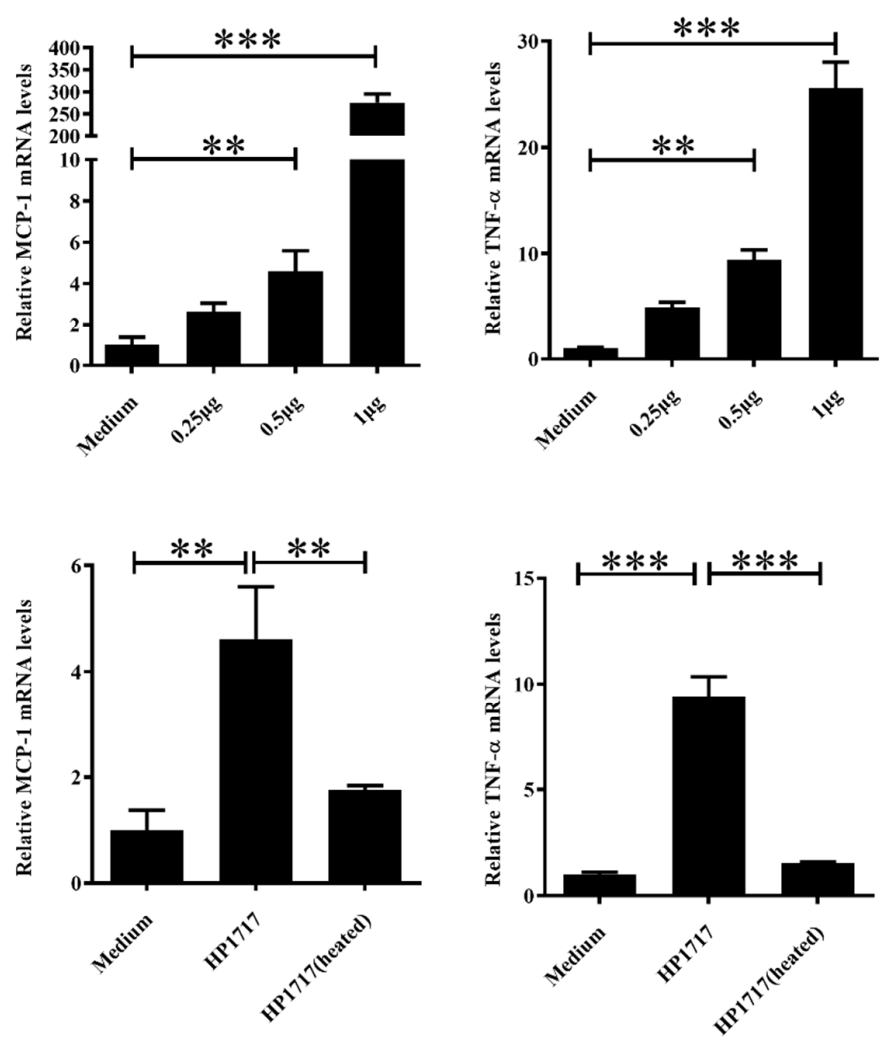

Figure 3. Experiments to determine the proinflammatory properties of HP1717. (A) The dose-dependent experiments were followed by qRT-PCR to measure transcript levels. (B) In the heat inactivation 
experiment, $1 \mu \mathrm{g} \cdot \mathrm{mL}^{-1} \mathrm{HP} 1717$ was inactivated by heating the protein at $100{ }^{\circ} \mathrm{C}$ for $10 \mathrm{~min}$ and then stimulating RAW264.7 cells with heat-inactivated HP1717. Then, the cytokine expression level was assessed by qRT-PCR. ${ }^{* *} p<0.01,{ }^{* * *} p<0.001$.
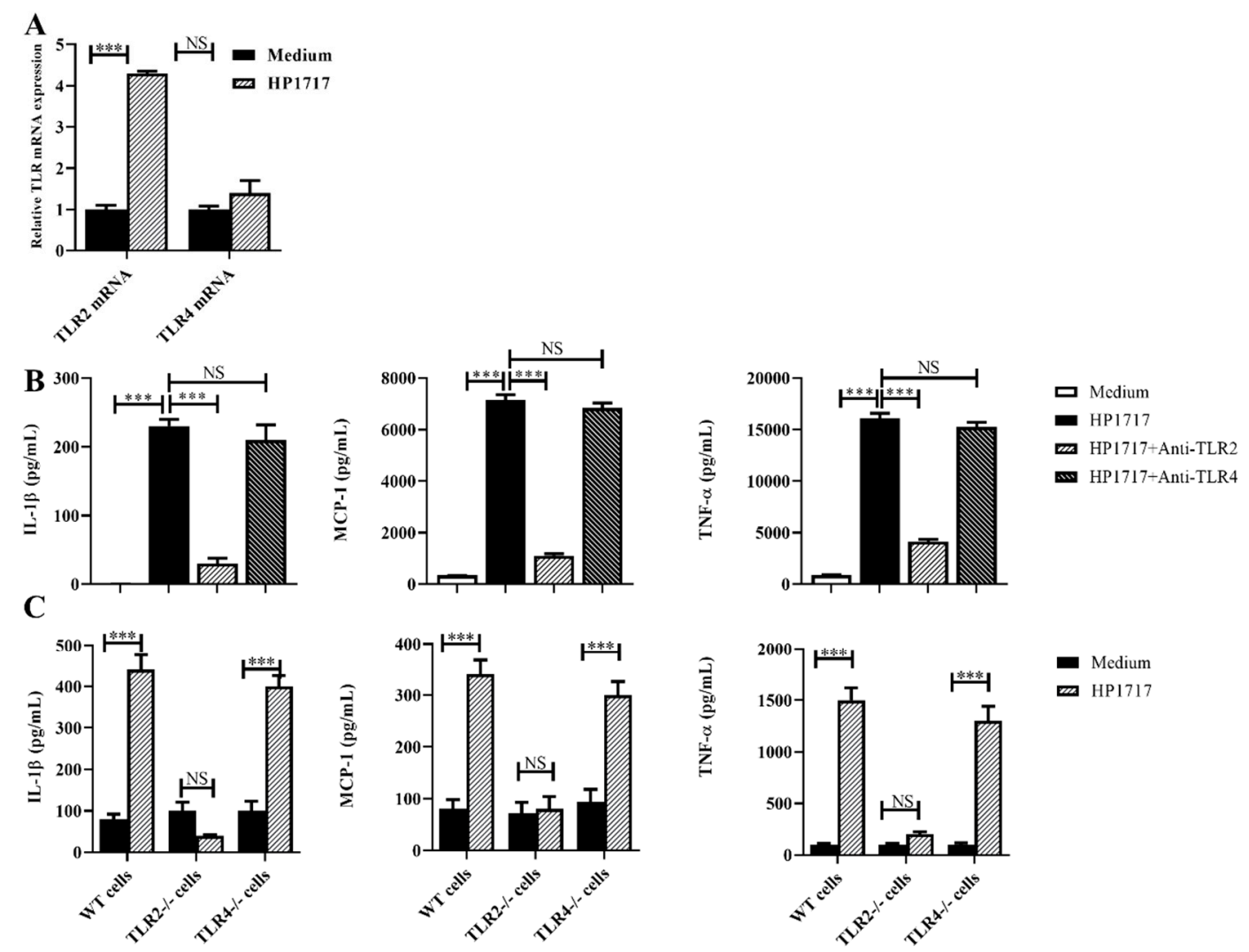

Figure 4. Recognition receptor of the HP1717-stimulated pro-inflammatory response. (A) After stimulation with HP1717, RAW264.7 cells were collected to analyze the mRNA levels of Toll-like receptor 2 (TLR2) or TLR4 by qRT-PCR. (B) Antibody blocking assays were conducted to determine the effects on cytokine expression. After pretreatment with $8 \mu \mathrm{g}$ of anti-TLR2 or anti-TLR4 antibodies for $30 \mathrm{~min}$, RAW 264.7 cells were incubated with $1 \mu \mathrm{g} \cdot \mathrm{mL}^{-1} \mathrm{HP} 1717$ for $6 \mathrm{~h}$. The concentrations of IL-1 $\beta$, MCP-1, and TNF- $\alpha$ were determined by ELISA. (C) After isolated from wild-type (WT), TLR2 ${ }^{-1-}$ and $\mathrm{TLR}^{-/-}$mice. The primary peritoneal macrophages were incubated with $1 \mu \mathrm{g} \cdot \mathrm{ml}^{-1} \mathrm{HP} 1717$ for $6 \mathrm{~h}$. The cytokine concentrations in the supernatants were determined by ELISA. ${ }^{* * *} p<0.001$; NS means no significant difference.

\subsection{The Pro-Inflammatory Role of HP1717 Depends on the Phosphorylation of NF- $\kappa B$ and ERK1/2}

To further investigate the pro-inflammatory mechanism of HP1717, we examined the HP1717dependent signaling pathway. We used inhibitors of p38 mitogen-activated protein kinase (MAPK), c-Jun N-terminal kinase (JNK), NF- $\mathrm{kB}$, phosphoinositide 3-kinase (PI3K), and ERK1/2 to identify the signaling pathways required for the pro-inflammatory response to HP1717. Our results show that U0126 and pyrrolidine dithiocarbamate (PDTC), which inhibit ERK1/2 and NF-kB, respectively, significantly suppressed the pro-inflammatory response to HP1717 (Figure 5A,B), suggesting that HP1717-induced cytokine expression probably depends on the phosphorylation of NF- $\mathrm{B}$ and ERK1/2. Western blot analysis was performed to verify this hypothesis. We found that HP1717 markedly stimulated the phosphorylation of NF- $\mathrm{BB}$ and ERK 1/2 MAPK in RAW264.7 cells compared with the control group (Figure 5C). All of the above experiments demonstrate that the HP1717-induced cytokine expression is dependent on the phosphorylation of NF- $\mathrm{KB}$ and ERK1/2. 
A
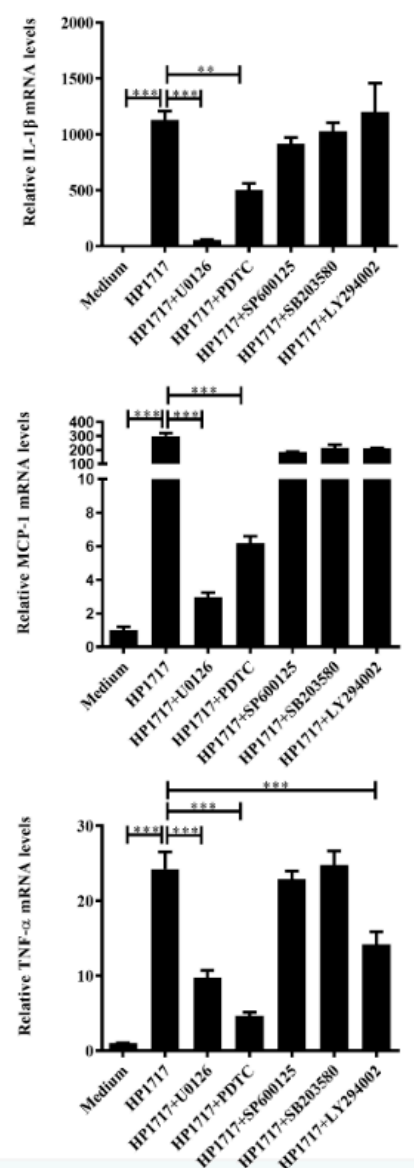
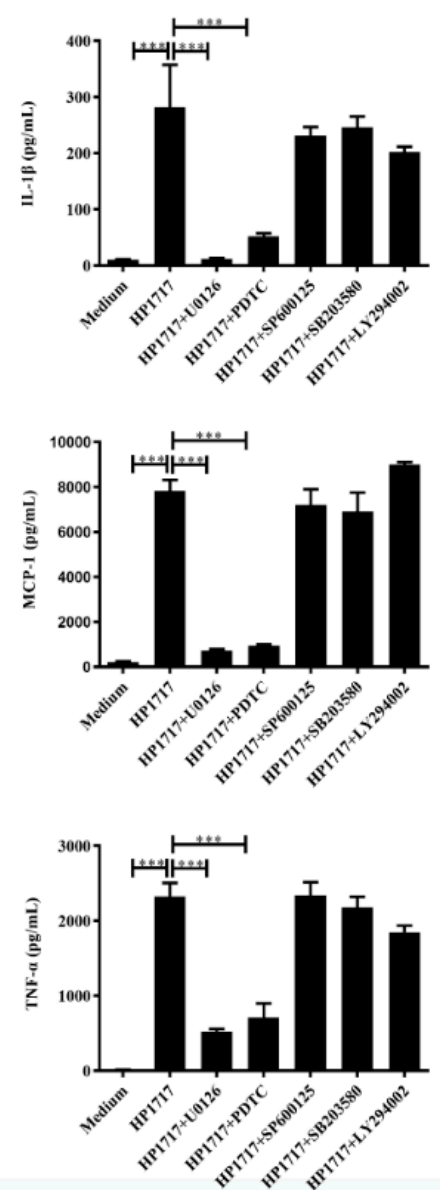

C

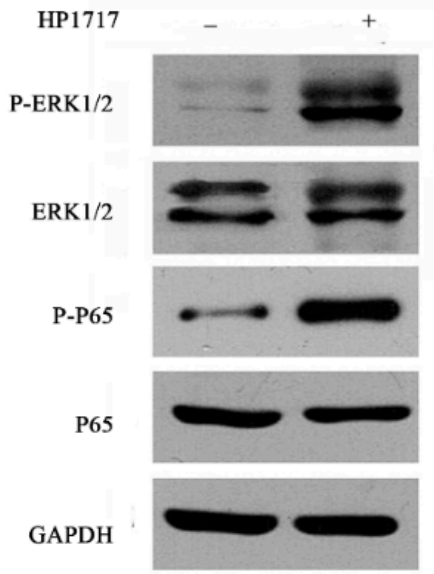

Figure 5. Signal transduction pathways of the HP1717-stimulated pro-inflammatory response in RAW 264.7 macrophages. After pretreatment with inhibitors of ERK1/2 (U0126), NF-kB (PDTC), JNK (SP600125), p38 MAPK (SB203580), or PI3K (LY294002) for $30 \mathrm{~min}$, RAW 264.7 macrophages were stimulated with $1 \mu \mathrm{g} \cdot \mathrm{mL}^{-1} \mathrm{HP} 1717$ for $6 \mathrm{~h}$. (A) The cytokine mRNA levels were determined by qRT-PCR, and (B) the protein levels of IL-1 $\beta$, MCP-1, and TNF- $\alpha$ in the culture supernatants were determined by ELISA. (C) HP1717-induced phosphorylation of NF- $\mathrm{BB}$ and ERK 1/2 MAPK in RAW264.7 macrophages: RAW264.7 macrophages were stimulated with HP1717 $\left(1 \mu \mathrm{g} \cdot \mathrm{mL}^{-1}\right)$ for $6 \mathrm{~h}$. The cell lysates were analyzed by Western blotting using specific antibodies against P65, phospho-P65, ERK 1/2 MAPK, and phospho-ERK 1/2 MAPK. GAPDH was detected as an internal control using an anti-GAPDH antibody. The results shown are representative of three independent experiments. $* * p<0.01, * * * 0.001$.

\subsection{Construction and Characterization of Mutant Strain $\Delta 1717$}

The deletion of the $h p 1717$ gene was verified by polymerase chain reaction (PCR) analysis. As shown in Figure $6 \mathrm{~A}$, the $g d h$ gene was detected in both $05 Z \mathrm{Y}$ and $\Delta 1717$ genomes (using primers $\mathrm{P} 1 / \mathrm{P} 2)$. On the contrary, the internal fragment of the $h p 1717$ gene (439 bp) could be detected in $05 Z \mathrm{Y}$ genome, but it was absent from the $\Delta 1717$ genome (using primers P5/P6). In addition, the pSET4s vector could not be amplified from the $\Delta 1717$ genome (using primers $P 3 / P 4)$. Furthermore, a large fragment (2071 bp) was obtained by amplifying the 05ZY genome with the external primers of $h p 1717$, and a small fragment (973 bp) was obtained by amplifying the $\Delta 1717$ genome. In summary, we successfully deleted the $h p 1717$ gene. Next, we examined the phenotypes of $\Delta 1717$. The growth curve indicates that the growth of $\Delta 1717$ was slightly slower than that of $05 Z Y$, but there were few differences between their curve peaks (Figure 6B). Interestingly, Gram staining results showed a significant increase in the chain length of $\Delta 1717$ (Figure 6C). To investigate whether CPS changed as a result of HP1717 deficiency, we examined the mutant and wild-type bacteria through transmission electron microscopy. 
Surprisingly, we found that the CPS of $\triangle 1717$ almost completely disappeared compared with that of $05 \mathrm{ZY}$ (Figure 6D). Since the significant change in the chain length of the mutant would lead to the inaccurate calculation of the mutant bacterial level by the conventional counting method (CFU counting), we used the absolute counting method on the basis of the $16 \mathrm{~S}$ gene levels in the mutant and wild-type bacteria as quantification criteria by qRT-PCR. A standard curve was plotted using the absolute quantification of the known amount of T vector with the 16S gene, and we determined bacterial levels by measuring the $16 \mathrm{~S}$ levels in $\Delta 1717$ and 05ZY. Bacterial levels in the subsequent experiments were determined by this method.
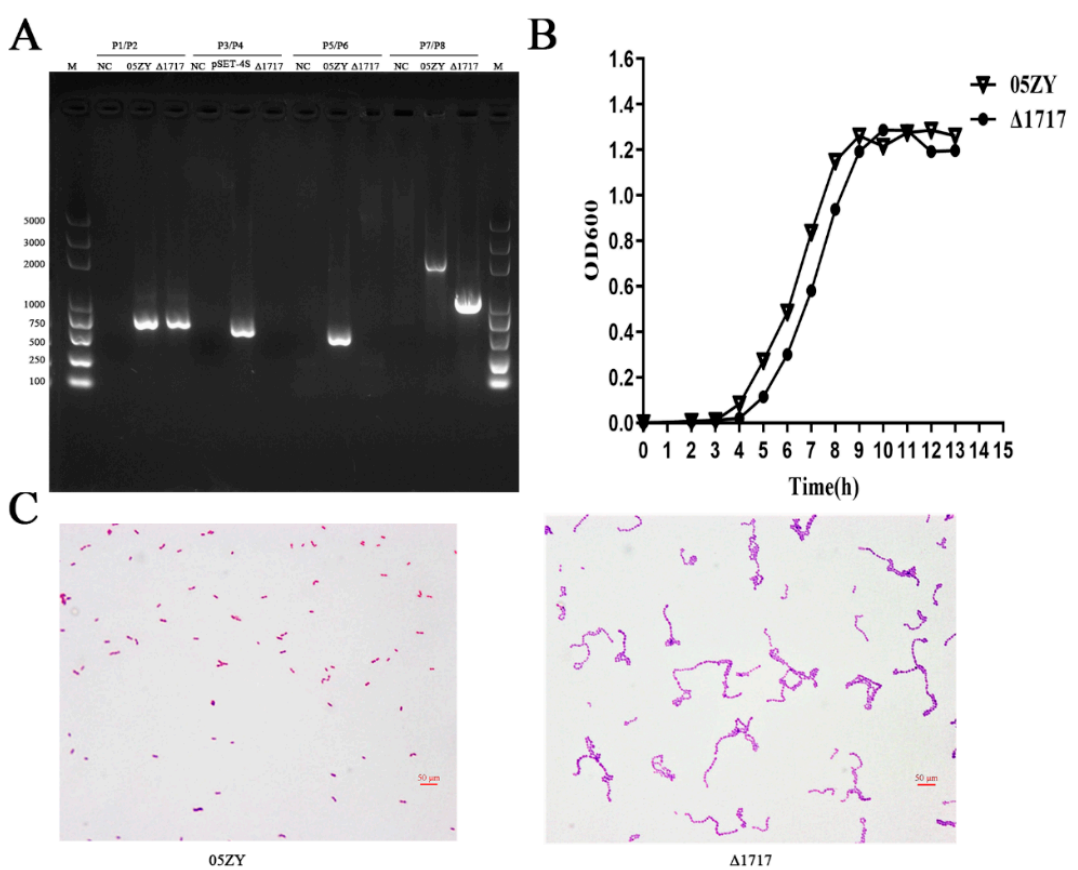

D
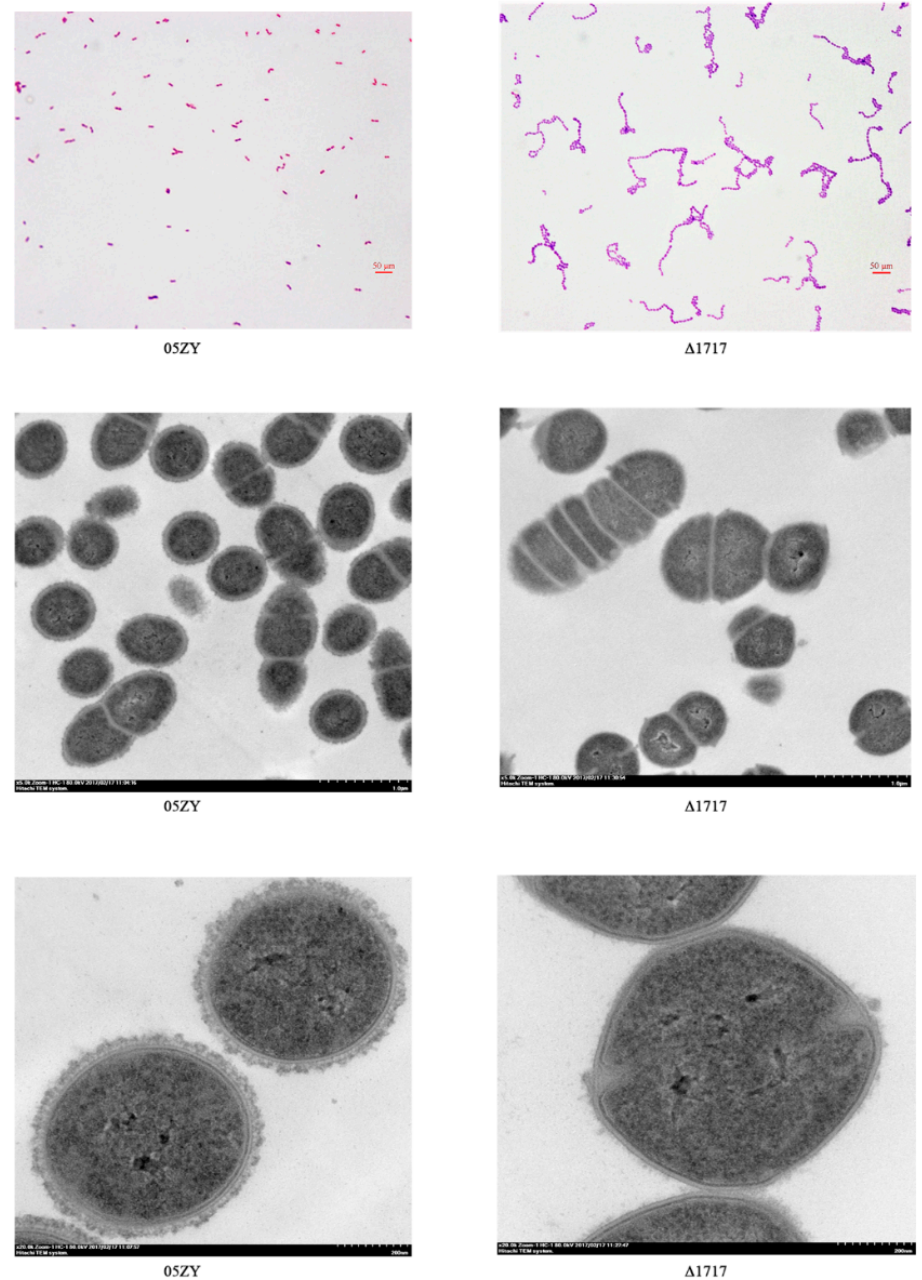

Figure 6. Construction and confirmation of the $\Delta 1717$ mutant. (A) Confirmation of the $\Delta 1717$ mutant by PCR using the primer pairs P1/P2 (to detect the $g d h$ gene), P3/P4 (to detect the pSET4s vector), P5/P6 
(to detect the $h p 1717$ gene), and P7/P8 (external primers of $h p 1717$ to distinguish the size of the wild type and mutant). (B) Growth curves of $05 \mathrm{ZY}$ and $\Delta 1717$ : the bacteria were cultured in tryptic soy broth (TSB) containing $5 \%$ newborn bovine serum at $37^{\circ} \mathrm{C}$. The absorbance at $600 \mathrm{~nm}$ was measured at intervals of $1 \mathrm{~h}$. The results shown are representative of three independent experiments. (C) Light microscope morphology of $05 Z \mathrm{Z}$ and $\Delta 1717$ were observed by Gram staining $(\times 1000)$. (D) The capsules of $05 Z Y$ and $\Delta 1717$ were detected by transmission electron microscopy (the top images are $\times 5000$, and the bottom images are $\times 20,000)$.

\section{8. $\Delta 1717$ Displays Reduced Resistance to Whole-Blood Killing}

The whole-blood sterilization assay was performed to determine the survival ability of $\Delta 1717$ in blood. The results show that the survival percentage of $\Delta 1717$ was significantly reduced compared with that of $05 \mathrm{ZY}$ at 0.5 and $1 \mathrm{~h}$ post-incubation, and the bacteria were completely cleared at $2 \mathrm{~h}$ (Figure 7), indicating that HP1717 may be involved in the resistance of the bacteria to whole-blood sterilization.

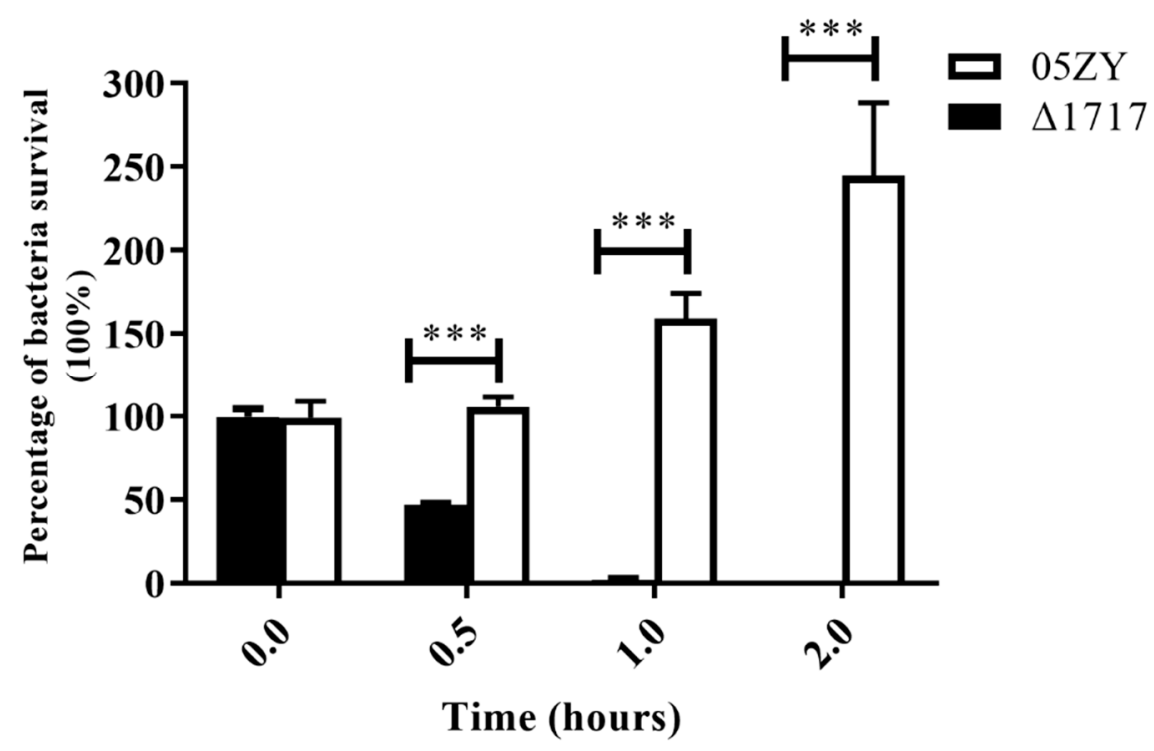

Figure 7. Whole-blood bactericidal experiment. First, $05 \mathrm{ZY}$ and $\Delta 1717$ were cultured to mid-log phase (OD600 $=0.6$ ). Then $1 \times 10^{4} \mathrm{CFU}$ of $05 \mathrm{ZY}$ or an equal quantity of $\Delta 1717$ was added into $1 \mathrm{~mL}$ of whole blood for $2 \mathrm{~h}$ at $37^{\circ} \mathrm{C}$. At $0,0.5,1$, and $2 \mathrm{~h}$ post incubation, bacterial counts were determined. The initial bacterial volume was set to $100 \%$, and the percentage of remaining bacteria was recorded at each time point. The assays were performed in triplicate and repeated three times. ${ }^{* * *} p<0.001$.

3.9. HP1717 Deficiency Leads to Attenuated Virulence, Decreased Pro-Inflammatory Ability, and Reduced Bacterial Loads in Mice

Mouse infection experiments were performed to investigate whether HP1717 influences the virulence of SS2. Because of the potential errors resulting from counting, we performed an absolute quantification experiment according to the above method. C57BL/6 mice were infected with $6 \times 10^{8}$ CFU of $05 Z Y$ or an equal quantity of $\Delta 1717$. The mice infected with $05 Z Y$ died within 2 days. On the contrary, $90 \%$ of the mice infected with $\Delta 1717$ survived for 7 days post-infection and showed no obvious symptoms (Figure 8A). These results indicate that HP1717 deficiency significantly reduced the virulence of SS2 in these mice. The cause of the reduced virulence was investigated by determining the cytokine concentrations in the blood and the bacterial loads in different organs. The blood of the mice infected with $\Delta 1717$ contained lower concentrations of IL- $1 \beta$, MCP-1, and TNF- $\alpha$ at 6,9 , and $12 \mathrm{~h}$ post-infection (Figure $8 \mathrm{~B}$ ). Results of the immunochemistry experiments show that the brown-yellow deposition in the lung, meninges, spleen, and kidney of the mice in the $\Delta 1717$ group was markedly lighter than that in the mouse organs in the 05ZY group (Figure 9), suggesting that the mice infected with $\Delta 1717$ contained lower bacterial loads in vivo. Finally, our results indicate that HP1717 may 
contribute to SS2 virulence by inducing high-level pro-inflammatory responses and influencing in vivo bacterial loads.
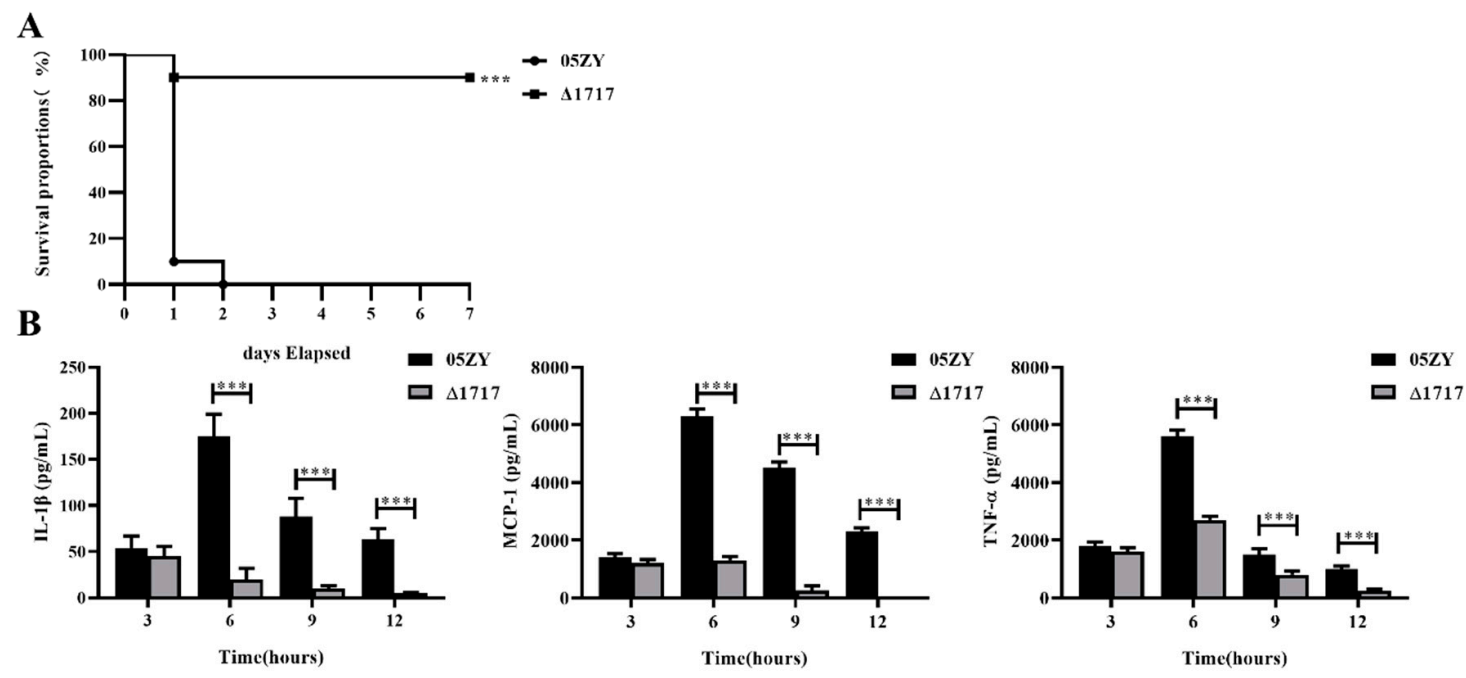

Figure 8. Mice infection and blood cytokine detection in an in vivo experiment. (A) Mice infection experiment. Female C57BL/6 mice in different groups were intraperitoneally infected with $6 \times 10^{8} \mathrm{CFU}$ of $05 \mathrm{ZY}$ or an equal quantity of $\Delta 1717$. The mortality of mice was recorded for 1 week. The results shown are representative of three independent experiments. (B) Blood cytokine detection in vivo experiment. Forty 4-week-old female C57BL/6 mice were randomly assigned to one of two groups (20 mice/group). One group was challenged with a non-lethal dose $\left(2 \times 10^{8} \mathrm{CFU}\right.$ per mouse) of 05ZY, and the other group was given an equal quantity of the $\Delta 1717$ strain. At $3,6,9$, and $12 \mathrm{~h}$ post-infection, five mice in each group were sacrificed to collect blood for ELISA detection of IL-1 $\beta, \mathrm{MCP}-1$, and TNF- $\alpha$ production. ${ }^{* * *} p<0.001$. 
$\triangle 1717$
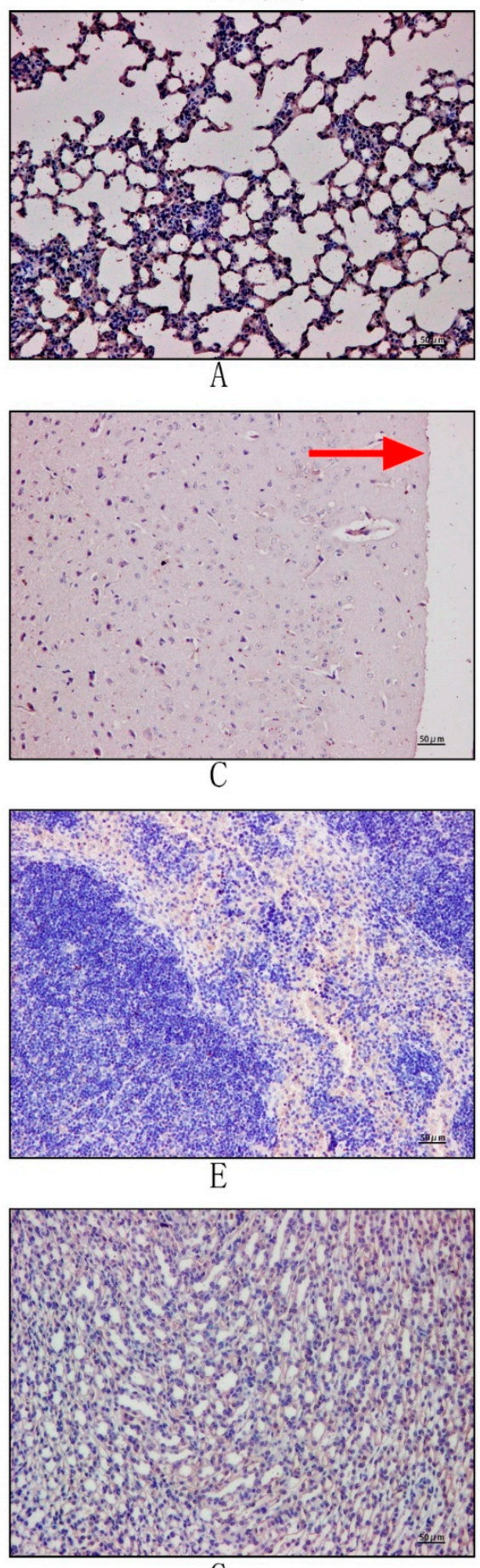

G
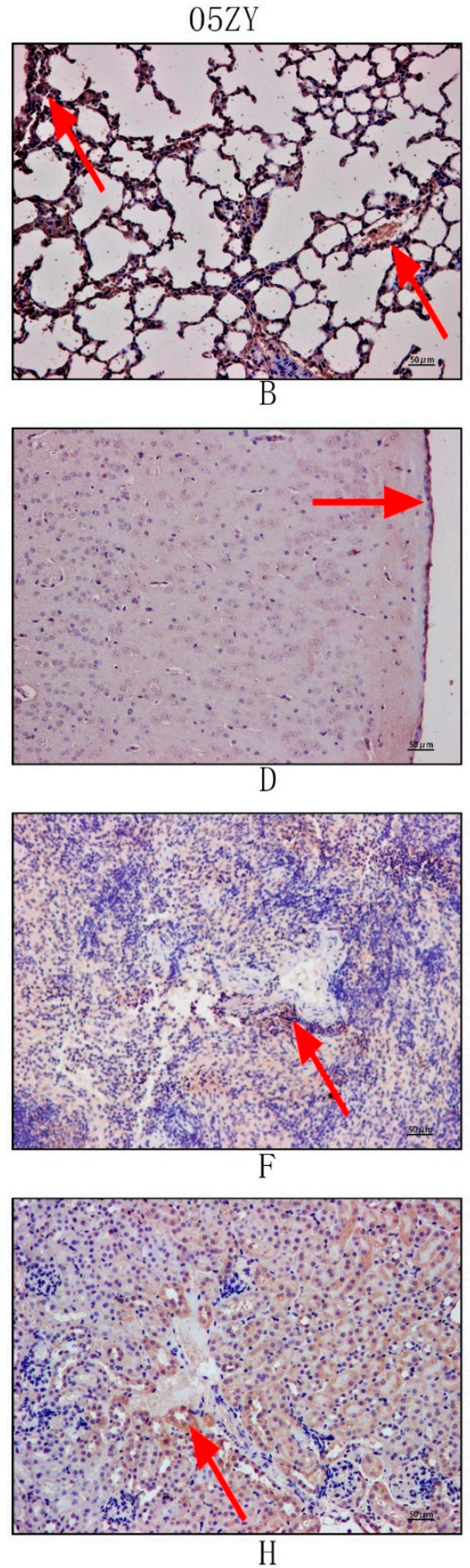

Figure 9. Immunohistochemistry of mouse organs after $\Delta 1717$ or $05 \mathrm{ZY}$ infection: 10 out of 30 (the remaining 20 were used for mice infection see Figure 8A) four-week-old male C57BL/6 mice were randomly divided into two groups, with 5 mice in each group. One group was intraperitoneally infected with $6 \times 10^{8} \mathrm{CFU}$ of $05 \mathrm{ZY}$, and the other group was given an equal quantity of $\Delta 1717$. After $6 \mathrm{~h}, 5$ mice in each group were sacrificed. The lungs, kidneys, spleens, and brains were extracted, fixed with paraformaldehyde for immunohistochemistry. The rehabilitation serum of pigs infected with 05ZY was used as the primary antibody for immunohistochemistry (1:300), and HRP Goat Anti-Swine IgG (H+L) was used as the secondary antibody (1:200) (Abclonal, Wuhan, China). (A,B) lungs; (C,D) meninges; (E,F) spleens; (G,H) kidney. 


\section{Discussion}

Currently, SS2 remains a high threat to the global swine industry and human health [24]. Two large-scale outbreaks of STSLS in China provoked extensive public health concerns worldwide [25]. Although investigations of STSLS have been ongoing since SS2 was discovered, the current knowledge of the mechanism by which SS2 induces STSLS remains limited. Excessive inflammation and high bacterial loads are two important hallmarks of STSLS caused by SS2 infection $[26,27]$, suggesting that clarification of the mechanisms of excessive inflammation and acute bacteremia resulting from SS2 infection would contribute to our understanding of SS2 pathogenesis, especially STSLS. In fact, the identification of some virulence-related factors has indeed enhanced our understanding of STSLS; for example, HP1330 can induce the pro-inflammatory response and influence in in vivo bacterial loads [13]. So, to further explain the mechanism of STSLS, it is necessary to identify additional molecules that can stimulate robust expression of pro-inflammatory cytokines and influence in in vivo bacterial loads. Our data demonstrate that HP1717 can induce a potent pro-inflammatory response in RAW264.7 cells. Furthermore, the deletion of HP1717 significantly reduces in vivo colonization of SS2. These findings suggest that HP1717 may be closely related to SS2-induced STSLS.

Generally, inflammation is beneficial to the host because it contributes to the clearance of the pathogen [28]. However, when an excessive inflammatory response is activated, the host can suffer serious damage [29]. A previous study indicated that, after SS2 infection, clearing the bacteria while not controlling excessive inflammation did not reduce the damage or death caused by SS2 infection [30], proving that an excessive inflammatory response is one of the important factors leading to pathological damage. In addition, as the most important virulence factor of S. suis, CPS can prevent host phagocytes from phagocytizing and killing bacteria [31,32], indicating that CPS is likely to be primarily responsible for immune evasion by S. suis. That is, excessive inflammation and the bacterial capsule are two of the most important factors of SS2 pathopoiesis. However, these two factors have not been considered at the same time in previous studies. Although CPS has been reported to induce the expression of several cytokines, high concentrations (at least $100 \mu \mathrm{g} \cdot \mathrm{mL}^{-1}$ purified CPS) were required to observe its pro-inflammatory ability $[33,34]$. Furthermore, there has been little evidence that CPS is responsible for excessive inflammation. Our results demonstrate that HP1717 can induce robust expression of pro-inflammatory cytokines, and it achieves this at a very low dose $\left(0.5 \mu \mathrm{g} \cdot \mathrm{mL}^{-1}\right.$; Figure $\left.3 \mathrm{~A}\right)$. At the same time, we also found that the deletion of HP1717 leads to almost the complete disappearance of CPS. Indeed, compared with the wild strain, the $\Delta 1717$ mutant displayed significantly reduced resistance to whole-blood killing and decreased in vivo bacterial loads. From the above results, we speculate that HP1717 can not only help SS2 escape or resist clearance by the host immune system by influencing the biosynthesis of CPS but also increase the SS2-induced pathological damage to the host by eliciting an excessive inflammatory response. Collectively, our data proved that HP1717 activity involves excessive inflammation and CPS at the same time. These findings lay the foundation for furthering our understanding of the pathogenesis of SS2.

Sequence homology analysis results suggest that HP1717 has certain similarity with MltG of E. coli and Streptococcus pneumoniae (S.pneumoniae) (Figure S1). Previous studies have shown that MltG has glycosyltransferase activity and can degrade peptidoglycan in E. coli [35]. But it didn't have the effect of degrading peptidoglycan in Streptococcus pneumoniae [36]. In our study, it was found by zymogram experiments that HP1717 has no peptidoglycan degradation suggesting that the protein may be closer to the function of S. pneumoniae (Figure S3). However, in our study the phenotype of S. suis changed greatly after $h p 1717$ deletion. The chain length of the pathogen was significantly longer and the CPS almost disappeared, which was very different from S. pneumoniae. Therefore, further research of the specific function of HP1717 in S. suis needs to be performed in future.

We attempted to construct a complementary bacterial strain of $\Delta 1717$, but we were not successful (in most cases, it is difficult to do this with S. suis), as was also reported previously [18,37]. To evaluate whether the deletion of the $h p 1717$ gene influences the expression of its adjacent gene, we performed qRT-PCR. We did not detect any significant changes in the expression levels of SSU05_1717-adjacent 
genes (SSU05_1716 and SSU05_1718) between 05ZY and $\Delta 1717$ (the results are not shown). To determine if any compensatory mutations might have occurred that could contribute to the phenotypes, whole genome sequence of the two strains were performed. The results showed that no meaningful compensatory mutations occurred in other locations, and genome sequencing and assembly data were uploaded to the Sequence Read Archive (SRA) under BioProject name PRJNA578680. In addition to CPS, we found that the chain length of SS2 is also significantly influenced by the deletion of HP1717. The chain length of $\Delta 1717$ increases by about 25 times compared with that of $05 Z$ Y, implying that the accuracy of bacterial counting would be highly erroneous using the conventional plate-counting method to compare the CFU count between $05 \mathrm{ZY}$ and $\triangle 1717$. To solve this problem, we inserted the $16 \mathrm{~S}$ housekeeping gene of $S$. suis into a vector. After concentrations were measured, the recombinant vectors were used to draw a standard curve. The $16 \mathrm{~S}$ levels in $05 \mathrm{ZY}$ and $\Delta 1717$ were measured by absolute quantitative PCR, and then the corresponding bacterial levels were calculated. Using this method, we performed all bacterial quantitation of $05 \mathrm{ZY}$ and $\Delta 1717$ before in vivo and in vitro experiments.

In conclusion, we identified HP1717 as a novel virulence-related factor of SS2 that can induce a potent pro-inflammatory response and influence the biosynthesis of CPS. Furthermore, our data demonstrated that the pro-inflammatory activity of HP1717 depends on the recognition of TLR2 and the phosphorylation of NF-KB and ERK1/2. These findings further expand our understanding of the pathogenesis and STSLS due to SS2.

Supplementary Materials: Supplementary materials can be found at http://www.mdpi.com/2076-2607/7/11/522/s1. Figure S1: Homology comparison between HP1717 and different bacterial homologous proteins; Figure S2: Cell surface localization confirmed by flow cytometry; Figure S3: Zymogram analysis. SDS-PAGE were stained by Coomassie Brilliant Blue (left) and Methylene Blue (right) separately.

Author Contributions: Conceptualization, M.J.; methodology, L.L.; investigation, L.L., Q.Z., Z.X., J.H., W.Z., and A.Z.; writing—original draft preparation, L.L.; writing—review and editing, L.L. and Q.Z.; project administration, X.S.; funding acquisition, M.J. and Z.Q.

Funding: This work was supported by the National Natural Science Foundation of China (31702253 and 31672557).

Acknowledgments: The authors thank Hubei general hospital (Wuhan, China) for providing transmission electron microscopy and Hycell Biotechnology Company (Wuhan, China) for immunohistochemistry.

Conflicts of Interest: The authors declare that there is no conflict of interest.

\section{References}

1. Votsch, D.; Willenborg, M.; Weldearegay, Y.B.; Valentin-Weigand, P. Streptococcus suis-The "Two Faces" of a Pathobiont in the Porcine Respiratory Tract. Front. Microbiol. 2018, 9, 480. [CrossRef]

2. Tien Le, H.T.; Nishibori, T.; Nishitani, Y.; Nomoto, R.; Osawa, R. Reappraisal of the taxonomy of Streptococcus suis serotypes 20,22, 26, and 33 based on DNA-DNA homology and sodA and recN phylogenies. Vet. Microbiol. 2013, 162, 842-849. [CrossRef]

3. Goyette-Desjardins, G.; Auger, J.P.; Xu, J.; Segura, M.; Gottschalk, M. Streptococcus suis, an important pig pathogen and emerging zoonotic agent-an update on the worldwide distribution based on serotyping and sequence typing. Emerg. Microbes Infect. 2014, 3, e45. [CrossRef]

4. Chen, C.; Tang, J.; Dong, W.; Wang, C.; Feng, Y.; Wang, J.; Zheng, F.; Pan, X.; Liu, D.; Li, M.; et al. A glimpse of streptococcal toxic shock syndrome from comparative genomics of S. suis 2 Chinese isolates. PLoS ONE 2007, 2, e315. [CrossRef]

5. Tang, J.; Wang, C.; Feng, Y.; Yang, W.; Song, H.; Chen, Z.; Yu, H.; Pan, X.; Zhou, X.; Wang, H.; et al. Streptococcal toxic shock syndrome caused by Streptococcus suis serotype 2. PLoS Med. 2006, 3, e151. [CrossRef]

6. Lun, Z.R.; Wang, Q.P.; Chen, X.G.; Li, A.X.; Zhu, X.Q. Streptococcus suis: An emerging zoonotic pathogen. Lancet Infect. Dis. 2007, 7, 201-209. [CrossRef]

7. Kerdsin, A.; Dejsirilert, S.; Puangpatra, P.; Sripakdee, S.; Chumla, K.; Boonkerd, N.; Polwichai, P.; Tanimura, S.; Takeuchi, D.; Nakayama, T.; et al. Genotypic profile of Streptococcus suis serotype 2 and clinical features of infection in humans, Thailand. Emerg. Infect. Dis. 2011, 17, 835-842. [CrossRef] [PubMed] 
8. Dominguez-Punaro, M.C.; Segura, M.; Plante, M.M.; Lacouture, S.; Rivest, S.; Gottschalk, M. Streptococcus suis serotype 2 , an important swine and human pathogen, induces strong systemic and cerebral inflammatory responses in a mouse model of infection. J. Immunol. 2007, 179, 1842-1854. [CrossRef] [PubMed]

9. Xu, Z.; Chen, B.; Zhang, Q.; Liu, L.; Zhang, A.; Yang, Y.; Huang, K.; Yan, S.; Yu, J.; Sun, X.; et al. Streptococcus suis 2 Transcriptional Regulator TstS Stimulates Cytokine Production and Bacteremia to Promote Streptococcal Toxic Shock-Like Syndrome. Front. Microbiol. 2018, 9, 1309. [CrossRef]

10. Zhao, J.; Pan, S.; Lin, L.; Fu, L.; Yang, C.; Xu, Z.; Wei, Y.; Jin, M.; Zhang, A. Streptococcus suis serotype 2 strains can induce the formation of neutrophil extracellular traps and evade trapping. FEMS Microbiol. Lett. 2015, 362, fnv022. [CrossRef]

11. Segura, M.; Fittipaldi, N.; Calzas, C.; Gottschalk, M. Critical Streptococcus suis Virulence Factors: Are They All Really Critical? Trends Microbiol. 2017, 25, 586-599. [CrossRef] [PubMed]

12. Dutkiewicz, J.; Zajac, V.; Sroka, J.; Wasinski, B.; Cisak, E.; Sawczyn, A.; Kloc, A.; Wojcik-Fatla, A. Streptococcus suis: A re-emerging pathogen associated with occupational exposure to pigs or pork products. Part IIPathogenesis. Ann. Agric. Environ. Med. 2018, 25, 186-203. [CrossRef] [PubMed]

13. Zhang, Q.; Huang, J.; Yu, J.; Xu, Z.; Liu, L.; Song, Y.; Sun, X.; Zhang, A.; Jin, M. HP1330 Contributes to Streptococcus suis Virulence by Inducing Toll-Like Receptor 2-and ERK1/2-Dependent Pro-Inflammatory Responses and Influencing in Vivo S. suis Loads. Front. Immunol. 2017, 8, 869. [CrossRef] [PubMed]

14. Yoshizawa, S.; Matsumura, T.; Ikebe, T.; Ichibayashi, R.; Fukui, Y.; Satoh, T.; Tsubota, T.; Honda, M.; Ishii, Y.; Tateda, K.; et al. Streptococcal toxic shock syndrome caused by beta-hemolytic streptococci: Clinical features and cytokine and chemokine analyses of 15 cases. J. Infect. Chemother. 2019, 25, 355-361. [CrossRef] [PubMed]

15. Gottschalk, M.; Xu, J.; Calzas, C.; Segura, M. Streptococcus suis: A new emerging or an old neglected zoonotic pathogen? Future Microbiol. 2010, 5, 371-391. [CrossRef] [PubMed]

16. Zhang, Q.; Yang, Y.; Yan, S.; Liu, J.; Xu, Z.; Yu, J.; Song, Y.; Zhang, A.; Jin, M. A novel pro-inflammatory protein of Streptococcus suis 2 induces the Toll-like receptor 2-dependent expression of pro-inflammatory cytokines in RAW 264.7 macrophages via activation of ERK1/2 pathway. Front. Microbiol. 2015, 6, 178. [CrossRef]

17. Takamatsu, D.; Osaki, M.; Sekizaki, T. Thermosensitive suicide vectors for gene replacement in Streptococcus suis. Plasmid 2001, 46, 140-148. [CrossRef]

18. Zheng, F.; Shao, Z.Q.; Hao, X.; Wu, Q.; Li, C.; Hou, H.; Hu, D.; Wang, C.; Pan, X. Identification of oligopeptide-binding protein (OppA) and its role in the virulence of Streptococcus suis serotype 2. Microb. Pathog. 2018, 118, 322-329. [CrossRef]

19. Hayashi, T.; Tsukagoshi, H.; Sekizuka, T.; Ishikawa, D.; Imai, M.; Fujita, M.; Kuroda, M.; Saruki, N. Next-generation DNA sequencing analysis of two Streptococcus suis ST28 isolates associated with human infective endocarditis and meningitis in Gunma, Japan: A case report. Infect. Dis. 2019, 51, 62-66. [CrossRef]

20. Tan, M.F.; Liu, W.Q.; Zhang, C.Y.; Gao, T.; Zheng, L.L.; Qiu, D.X.; Li, L.; Zhou, R. The involvement of MsmK in pathogenesis of the Streptococcus suis serotype 2. MicrobiologyOpen 2017, 6, e00433. [CrossRef]

21. Pian, Y.; Gan, S.; Wang, S.; Guo, J.; Wang, P.; Zheng, Y.; Cai, X.; Jiang, Y.; Yuan, Y. Fhb, a novel factor H-binding surface protein, contributes to the antiphagocytic ability and virulence of Streptococcus suis. Infect. Immun. 2012, 80, 2402-2413. [CrossRef] [PubMed]

22. Bartual, S.G.; Straume, D.; Stamsas, G.A.; Munoz, I.G.; Alfonso, C.; Martinez-Ripoll, M.; Havarstein, L.S.; Hermoso, J.A. Structural basis of PcsB-mediated cell separation in Streptococcus pneumoniae. Nat. Commun. 2014, 5, 3842. [CrossRef] [PubMed]

23. Liu, L.; Cheng, G.; Wang, C.; Pan, X.; Cong, Y.; Pan, Q.; Wang, J.; Zheng, F.; Hu, F.; Tang, J. Identification and experimental verification of protective antigens against Streptococcus suis serotype 2 based on genome sequence analysis. Curr. Microbiol. 2009, 58, 11-17. [CrossRef] [PubMed]

24. Huang, K.S.; Yuan, Z.Z.; Li, J.T.; Zhang, Q.; Xu, Z.M.; Yan, S.X.; Zhang, A.D.; Jin, M.L. Identification and characterisation a surface-associated arginine peptidase in Streptococcus suis serotype 2. Microbiol. Res. 2015, 170, 168-176. [CrossRef]

25. Normile, D. Infectious diseases. WHO probes deadliness of China's pig-borne disease. Science 2005, 309, 1308-1309. [CrossRef]

26. Ye, C.; Zheng, H.; Zhang, J.; Jing, H.; Wang, L.; Xiong, Y.; Wang, W.; Zhou, Z.; Sun, Q.; Luo, X.; et al. Clinical, experimental, and genomic differences between intermediately pathogenic, highly pathogenic, and epidemic Streptococcus suis. J. Infect. Dis. 2009, 199, 97-107. [CrossRef] 
27. Bi, Y.H.; Li, J.; Yang, L.M.; Zhang, S.; Li, Y.; Jia, X.J.; Sun, L.; Yin, Y.B.; Qin, C.; Wang, B.N.; et al. Assessment of the pathogenesis of Streptococcus suis type 2 infection in piglets for understanding streptococcal toxic shock-like syndrome, meningitis, and sequelae. Vet. Microbiol. 2014, 173, 299-309. [CrossRef]

28. Martinon, F.; Tschopp, J. NLRs join TLRs as innate sensors of pathogens. Trends Immunol. 2005, 26, 447-454. [CrossRef]

29. Kahn, F.; Morgelin, M.; Shannon, O.; Norrby-Teglund, A.; Herwald, H.; Olin, A.I.; Bjorck, L. Antibodies against a surface protein of Streptococcus pyogenes promote a pathological inflammatory response. PLoS Pathog. 2008, 4, e1000149. [CrossRef]

30. Yang, C.; Zhao, J.; Lin, L.; Pan, S.; Fu, L.; Han, L.; Jin, M.; Zhou, R.; Zhang, A. Targeting TREM-1 Signaling in the Presence of Antibiotics is Effective Against Streptococcal Toxic-Shock-Like Syndrome (STSLS) Caused by Streptococcus suis. Front. Cell. Infect. Microbiol. 2015, 5, 79. [CrossRef]

31. Smith, H.E.; Damman, M.; van der Velde, J.; Wagenaar, F.; Wisselink, H.J.; Stockhofe-Zurwieden, N.; Smits, M.A. Identification and characterization of the cps locus of Streptococcus suis serotype 2: The capsule protects against phagocytosis and is an important virulence factor. Infect. Immun. 1999, 67, 1750-1756. [PubMed]

32. Segura, M.; Gottschalk, M.; Olivier, M. Encapsulated Streptococcus suis inhibits activation of signaling pathways involved in phagocytosis. Infect. Immun. 2004, 72, 5322-5330. [CrossRef] [PubMed]

33. Graveline, R.; Segura, M.; Radzioch, D.; Gottschalk, M. TLR2-dependent recognition of Streptococcus suis is modulated by the presence of capsular polysaccharide which modifies macrophage responsiveness. Int. Immunol. 2007, 19, 375-389. [CrossRef] [PubMed]

34. Tanabe, S.; Bonifait, L.; Fittipaldi, N.; Grignon, L.; Gottschalk, M.; Grenier, D. Pleiotropic effects of polysaccharide capsule loss on selected biological properties of Streptococcus suis. Can. J. Vet. Res. 2010, 74, 65-70.

35. Yunck, R.; Cho, H.; Bernhardt, T.G. Identification of MltG as a potential terminase for peptidoglycan polymerization in bacteria. Mol. Microbiol. 2016, 99, 700-718. [CrossRef]

36. Tsui, H.C.; Zheng, J.J.; Magallon, A.N.; Ryan, J.D.; Yunck, R.; Rued, B.E.; Bernhardt, T.G.; Winkler, M.E. Suppression of a deletion mutation in the gene encoding essential PBP2b reveals a new lytic transglycosylase involved in peripheral peptidoglycan synthesis in Streptococcus pneumoniae D39. Mol. Microbiol. 2016, 100, 1039-1065. [CrossRef]

37. Gao, T.; Tan, M.; Liu, W.; Zhang, C.; Zhang, T.; Zheng, L.; Zhu, J.; Li, L.; Zhou, R. GidA, a tRNA Modification Enzyme, Contributes to the Growth, and Virulence of Streptococcus suis Serotype 2. Front. Cell. Infect. Microbiol. 2016, 6, 44. [CrossRef]

(C) 2019 by the authors. Licensee MDPI, Basel, Switzerland. This article is an open access article distributed under the terms and conditions of the Creative Commons Attribution (CC BY) license (http://creativecommons.org/licenses/by/4.0/). 